\title{
TSPY is a cancer testis antigen expressed in human hepatocellular carcinoma
}

\author{
Y-H Yin ${ }^{1,2}$, Y-Y Li ${ }^{1,2}$, H Qiao ${ }^{1,2}$, H-C Wang', X-A Yang', H-G Zhang', X-W Pang', Y Zhang' and W-F Chen*,1 \\ 'Immunology Department, Peking University Health Science Center, Beijing 100083, China
}

\begin{abstract}
In search for genes associated with hepatocellular carcinoma (HCC) by cDNA microarray, we found that the transcription of TSPY, 'testis-specific protein Y-encoded', was upregulated in HCC. Investigation of a broad spectrum of normal and malignant tissues by RT-PCR revealed the TSPY transcript selectively expressed in normal testis, different histological types of human neoplastic tissues, and tumour cell lines. The expression of TSPY in cancer cells was further confirmed by in situ hybridisation. Indirect immunofluorescence microscopy analysis showed that TSPY was localised mainly in the cytoplasm of transiently transfected cells. Testis-specific protein Y-encoded was detected in 50\% ( 16 of 32) of well- and moderately differentiated HCC patients, in 16\% (four of 25) of poorly differentiated HCC patients, and in $5 \%$ (one of 19) of renal cell cancer patients. A serological survey revealed that $6.6 \%$ (seven of 106) HCC patients had anti-TSPY antibody response, demonstrating the immunogenicity of TSPY in humans. In conclusion, these data suggest that TSPY is a novel cancer/testis (CT) antigen and may be a potential candidate in vaccine strategy for immunotherapy in HCC patients.
\end{abstract}

British Journal of Cancer (2005) 93, 458-463. doi:I0.1038/sj.bjc.66027I6 www.bjcancer.com

Published online 2 August 2005

(c) 2005 Cancer Research UK

Keywords: testis-specific protein Y-encoded; hepatocellular carcinoma; CT antigen; antibody response; immunotherapy

Hepatocellular carcinoma (HCC), the major type of primary liver cancer, is one of the most prevalent cancers worldwide, and is markedly increasing in incidence because of the dissemination of hepatitis B and C virus infection (Llovet et al, 2003). Despite the remarkable advances in diagnostic and therapeutic techniques, prognosis of HCC still remains extremely poor ranking as the third highest cause of cancer death (Butterfield and Ribas, 2002). Therefore, the innovative and potentially disease-specific therapies for HCC are of great concern. Antigen-specific immunotherapy, as an alternative approach for treatment of HCC, is attractive due to the exquisite specificity of the immune response. Recent reports indicated that a subset of immunotherapy trials for HCC had shown clinical effects (Iwashita et al, 2003; Butterfield, 2004; Kuang et al, 2004). A prerequisite for a broad application of antigenspecific immunotherapy is the identification of appropriate target antigens capable of inducing an immune response. The discovery of cancer/testis (CT) antigens, which express in a broad spectrum of neoplasms but not in normal tissues except in testis and placenta, has provided new perspectives for antigen-specific immunotherapy (Scanlan et al, 2002). To date, $44 \mathrm{CT}$ gene families have been identified, and the protein products of 19 gene families have been demonstrated to elicit immune responses in human (Scanlan et al, 2004). The immunogenicity and restricted expression of CT antigens make them ideal candidates for specific cancer

*Correspondence: Dr W-F Chen; E-mail: wfchen@public.bta.net.cn

${ }^{2}$ These authors contributed equally to this work

Received 29 March 2005; revised 7 June 2005; accepted 20 June 2005; published online 2 August 2005 immunity. However, the known CT antigens are expressed in only a fraction of cases of a given tumour type, and the progressive loss of tumour antigens is due to the immunoselection in the course of vaccination, the identification of additional $\mathrm{CT}$ antigens is urgently needed for developing polyvalent tumour vaccines to improve the efficacy of immunotherapy (Kalos, 2003).

Recent development of cDNA microarray technology has opened a new era in medical sciences. Several studies demonstrated the usefulness of this technique for identifying novel cancer-related genes and for disclosing genetic mechanisms in cancers (Okabe et al, 2001; Iizuka et al, 2002; Smith et al, 2003). We have performed cDNA microarray analysis for mining differentially expressed genes during the progress of HCC in an attempt to provide clues for identifying new therapeutic targets (Shi et al, 2005). In this study, we identified TSPY, 'testis-specific protein Y-encoded', which was overexpressed in human HCC, as based on cDNA microarray data. We examined TSPY mRNA expression in tumours of different histological types and the seroreactivity against TSPY in HCC patients, suggesting that TSPY is a novel CT antigen capable of eliciting antibody response in HCC patients. Testis-specific protein Y-encoded may provide a novel therapeutic target for immunotherapy in HCC patients.

\section{MATERIALS AND METHODS}

\section{Tissues, sera, and cell lines}

Tumour tissues, paired noncancerous tissues, and serum samples were obtained with informed consent from patients who underwent surgical resection at the 2nd School of Clinical Medicine, 
Peking University Health Science Center, China. All the samples are from male patients. Tissues destined for RNA extraction were kept frozen in liquid nitrogen immediately after separation. Tissue samples for in situ hybridisation were fixed in $4 \%$ formalin solution and embedded in paraffin. Serum samples were stored at $-70^{\circ} \mathrm{C}$ freezer.

Hepatocellular carcinoma cell lines (HLE: nondifferentiated, derived from a 68-year-old male patient; Hep3B: well differentiated (WD), derived from 8-year-old male patient) and COS7 cells were obtained from Shanghai Institute of Cell Biology, Chinese Academy of Sciences (Shanghai, People's Republic of China). The other six moderately to poorly differentiated (PD) HCC cell lines of male origin, Hep-hcc-1, Hep-hcc-2, Hep-hcc-3, Hep-hcc-4, Hep-hcc-5, and Hep-hcc-6, are the gifts kindly given by Professor Ya-Jun Guo, the Second Military Medical University, China. The cDNA of melanoma (derived from male), lung (derived from male), breast, pancreas, colon (derived from female), prostate, and ovary cell lines were purchased from Clontech Laboratories Inc. (Palo Alto, CA, USA).

\section{RT - PCR}

The expression pattern of TSPY transcript was determined by RT PCR. In all, 16 different normal tissue cDNA preparations, including heart (pooled from three male Caucasians), brain (pooled from two male Caucasians), placenta, lung (pooled from two female Caucasians), liver (pooled from three male Caucasians), skeletal muscle (pooled from eight male/female Caucasians), kidney (pooled from five male/female Caucasians), pancreas (pooled from 15 male/female Caucasians), spleen (pooled from three male/female Caucasians), thymus (pooled from 18 male/ female Caucasians), prostate, testis, ovary, small intestine (pooled from 32 male/female Caucasians), colon (pooled from 20 male/ female Caucasians), and peripheral blood leucocyte (pooled from 550 male/female Caucasians), were purchased from Clontech Laboratories Inc. (Palo Alto, CA, USA). RNA samples extracted from tumour tissues, paired adjacent nontumour tissues, and cell lines were reversely transcribed with advantage reverse transcriptase (Clontech, Palo Alto, CA, USA). PCR primers specific for amplifying TSPY transcript were: forward, 5'-CAGGGCTTCT CATTCCACTC- $3^{\prime}$; and reverse, 5'-CCATCATATTCAACTCAA CAACTGG-3' $3^{\prime}$ PCR was performed with 32 cycles of $20 \mathrm{~s}$ at $94^{\circ} \mathrm{C}$, $20 \mathrm{~s}$ at $58^{\circ} \mathrm{C}$, and $20 \mathrm{~s}$ at $72^{\circ} \mathrm{C}$, followed by $7 \mathrm{~min}$ at $72^{\circ} \mathrm{C}$. The amplified products were analysed on $2 \%$ agarose/Tris-acetateEDTA gels stained with ethidium bromide. The integrity and quantity of the cDNA were evaluated by amplification of glyceraldehyde-3-phosphate dehydrogenase (G3PDH).

\section{In situ hybridisation}

Sense and antisense probes were synthesised using T7 or SP6 with a DIG labelling kit (Roche Diagnostics, Switzerland) to generate TSPY-labelled riboprobes. The tissue sections $(5 \mu \mathrm{m})$ were deparaffinised, rehydrated, and incubated in $0.2 \mathrm{M} \mathrm{HCl}$ for 20 min. After washing with PBS, the tissues were treated with proteinase $\mathrm{K}$ at a concentration of $20 \mu \mathrm{g} \mathrm{ml}^{-1}$ for $15 \mathrm{~min}$ at $37^{\circ} \mathrm{C}$. After fixation with $4 \%$ paraformaldehyde for $5 \mathrm{~min}$ and washing in PBS, the sections were prehybridised for $1 \mathrm{~h}$ at $50^{\circ} \mathrm{C}$ in a buffer containing $50 \%\left(\mathrm{vv}^{-1}\right)$ formamide, $4 \times \mathrm{SSC}, 2 \times$ Denhardts solution, and $250 \mu \mathrm{g} \mathrm{ml}^{-1}$ RNA. Hybridisation was performed overnight at the same temperature in $50 \%\left(\mathrm{v} \mathrm{v}^{-1}\right)$ formamide, $4 \times \mathrm{SSC}$, $2 \times$ Denhardts solution, $500 \mu \mathrm{g} \mathrm{ml}^{-1}$ RNA, $10 \%$ dextran sulphate, and $2 \mu \mathrm{g} \mathrm{ml}^{-1}$ DIG-labelled probes. Excess probes were removed by washing with $2 \times$ SSC containing $50 \%$ formamide followed by RNase $\left(250 \mu \mathrm{g} \mathrm{ml}^{-1}\right)$ treatment at $37^{\circ} \mathrm{C}$ for $30 \mathrm{~min}$. Tissues were washed at $37^{\circ} \mathrm{C}$ in $2 \times$ SSC and $0.2 \times$ SSC. Then, the sections were incubated with alkaline phosphatase (AP)-conjugated anti-DIG Ab
(Roche). Colour development was processed with nitroblue tetrazolium and 5-bromo-4-chloro-3-indolyl phosphate.

\section{Cell transfection and immunofluorescence}

For localisation studies, we constructed the expression plasmid pcDNA-TSPY-FLAG by cloning a fragment containing the fulllength ORF minus the termination codon in the HindIII-BamHI sites of pcDNA-FLAG vector. The in-frame junction was confirmed by sequencing. COS7 cells were transfected with either vector alone as a control or vector with TSPY insert, using LipofectAMINE 2000 (Invitrogen, CA, USA), following the manufacturer's instructions. After incubation at $37^{\circ} \mathrm{C}$ for $24 \mathrm{~h}$, cells were fixed with precooled $100 \%$ methanol at $-20^{\circ} \mathrm{C}$ for $15 \mathrm{~min}$. The fixed cells were blocked with $1 \%$ nonfat milk in PBS for $1 \mathrm{~h}$ and stained with anti-FLAG M2 mouse monoclonal antibody (mAb) (Sigma, USA) for $1 \mathrm{~h}$ at room temperature (RT), followed by incubation with TRITC (tetramethylrhodamine isothiocyanate)-conjugated anti-mouse immunoglobulin $\mathrm{G}$ antibody (IgG $\mathrm{Ab}$ ) for $1 \mathrm{~h}$ at RT, and then cell nuclei were stained with Hoechst 33342 for $10 \mathrm{~min}$ at $37^{\circ} \mathrm{C}$. Images were obtained using a fluorescence microscope equipped with a Charge Couple Device camera.

\section{Western blot analysis}

At $24 \mathrm{~h}$ after transfection, cultured cells were lysed in $2 \times$ SDS sample buffer (0.1 м Tris-HCl, $\mathrm{pH} 6.8 / 0.2 \mathrm{M}$ DTT/4\% SDS/0.2\% bromophenol blue $/ 20 \%$ glycerol), and then separated by $12.5 \%$ SDS - polyacrylamide gel electrophoresis, followed by transfer to nitrocellulose membranes. After blocking in TNT solution containing $5 \%$ nonfat milk, the membrane was incubated with anti-FLAG $\mathrm{mAb}$ (Sigma) at RT for $1 \mathrm{~h}$, followed by incubation with a horseradish peroxidase-linked goat anti-mouse IgG at RT for $1 \mathrm{~h}$. Colour development was performed through incubation with $3,3^{\prime}$ diaminobenzidine tetrahydrochloride in $0.03 \% \mathrm{H}_{2} \mathrm{O}_{2}$ and $50 \mathrm{~mm}$ Tris-HCl, pH 7.4.

\section{Seroreactivity analysis of TSPY}

To analyse the presence of anti-TSPY Ab in HCC patient's sera, the full-length TSPY cDNA was cloned in the expression vector pET28a $(+)$, and recombinant TSPY protein was produced in Escherichia coli with the induction of $1 \mathrm{~mm}$ IPTG at $42^{\circ} \mathrm{C}$ for $6 \mathrm{~h}$. After purification by $\mathrm{Ni}^{2+}$ affinity chromatography, the recombinant TSPY protein fused with $6 \times$ His tag was separated on $12.5 \%$ SDS-polyacrylamide gel electrophoresis, followed by transfer to nitrocellulose membrane. After blocking in TNT solution containing $5 \%$ nonfat milk, the membranes were incubated with sera from HCC patients at a $1: 100$ dilution for $1.5 \mathrm{~h}$, and then with APconjugated goat anti-human IgG (Promega, USA). Serum IgG reactivity was detected with the AP substrate, 4-nitroblue tetrazolium chloride/5-bromo-4-chloro-3-indolylphosphate. AntiHis antibody (Qiagen) at a 1:5000 dilution was used for positive control.

\section{RESULTS}

\section{Expression of TSPY mRNA in normal and tumour tissues}

To examine the distribution of TSPY gene expression, RT-PCR was performed using cDNA reversed from mRNA of normal tissues, tumours, and cancer cell lines. Testis-specific protein $\mathrm{Y}$ encoded mRNA was restricted to testis and was not detected in the various normal tissues tested, including liver, spleen, prostate, pancreas, ovary, colon, small intestine, heart, lung, peripheral blood leucocyte, brain, kidney, placenta, skeletal muscle, and thymus (Figure 1A). As the lung cDNA obtained from Clontech was of female origin, TSPY expression was further measured in 
460
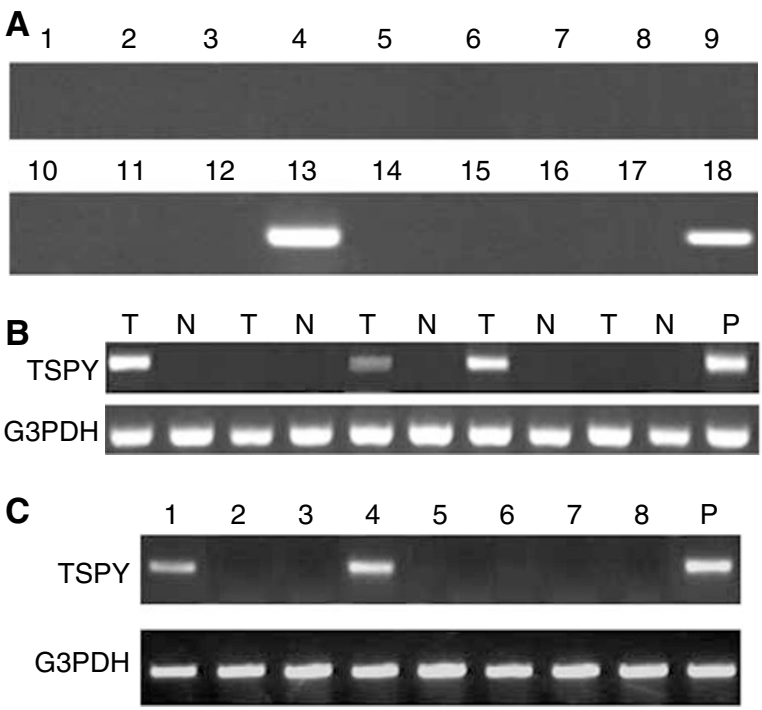

Figure I Expression of TSPY mRNA in normal and malignant tissues. Testis-specific protein Y-encoded mRNA expression was analysed by RTPCR. (A) TSPY mRNA was expressed only in normal testis but not in other tissues. Lane I: brain; 2: heart; 3: kidney; 4: liver; 5: lung; 6: pancreas; 7: skeletal muscle; 8: placenta; 9: ovary; 10: thymus; I I: prostate; 12: spleen; 13: testis; 14: small intestine; 15: colon; 16: leucocytes; 17: negative control; 18: positive control (testis as a positive control). (B) Expression of TSPY mRNA in HCC tissues. Representative expression pattern is shown in some HCC samples; testis mRNA was used as a positive control. RT-PCR for G3PDH was used to monitor the quality of the RNA sample. ( $T$ : cancerous tissues; $\mathrm{N}$ : adjacent noncancerous tissues; P: positive control). (C) Expression of TSPY mRNA in HCC cell lines. Lane I: hep-hcc-I; lane 2: hep-hcc-2; lane 3: hep-hcc-3; lane 4: hep-hcc-4; lane 5: hep-hcc-5; lane 6: hep-hcc-6; lane 7: HLE; lane 8: Hep3B; P: positive control (testis as a positive control). RT-PCR for G3PDH was used to monitor the quality of the RNA sample.

normal lung tissues we collected from male patients and there was no detectable TSPY transcript. In addition, a number of tumours of various histological types expressed TSPY (Table 1). The TSPY was expressed in $35.1 \%$ ( 20 of 57 ) of HCC samples (Figure 1B). A less frequent expression was detected in renal cell cancer (one of 19). However, no expression was found in gastric cancer, lung cancer, bladder cancer and leukaemia samples. Histopathological diagnosis showed that, of the 57 HCC samples, 15 were WD, 17 were moderately differentiated (MD), and 25 were $\mathrm{PD}$. The positive frequency of TSPY mRNA was $50 \%$ (16 of 32) in WD and MD, and $16 \%$ (four of 25) in PD HCC tissue samples. The expression of TSPY mRNA was in the HCC cells as demonstrated by in situ hybridisation analysis (Figure 2).

Of the eight HCC cell lines tested (HLE, Hep3B, hep-hcc-1, hephcc-2, hep-hcc-3, hep-hcc-4, hep-hcc-5, hep-hcc-6), TSPY mRNA was detected in hep-hcc-1 and hep-hcc-4 cell lines (Figure 1C). Among other nine cancer cell lines tested, including melanoma, ME235; lung, LX-1 and G1-117; breast, G1-101; pancreas, G1-103; colon, CX-1 and G1-112; prostate, PC3; and ovary, G1-102, TSPY was only expressed in melanoma cell line ME235.

\section{Subcellular localisation of TSPY}

To determine the subcellular localisation of TSPY, indirect immunofluorescence for tagged TSPY was performed. FLAGtagged TSPY expression plasmid was transfected into COS7 cells. Indirect immunofluorescence assay with anti-FLAG Ab demonstrated that FLAG-tagged TSPY was mainly in the cytoplasm of transfected COS7 cells (Figure 3). Testis-specific protein Y-
Table I Expression of TSPY transcript in malignant tissues

\begin{tabular}{lc}
\hline Tumour type & TSPY expression, no. positive/no. tested \\
\hline HCC & $20 / 57$ \\
Renal cell carcinoma & $1 / 19$ \\
Lung carcinoma NSCLC & $0 / 13$ \\
Bladder cancer & $0 / 8$ \\
Lymphoma or leukaemia & $0 / 11$ \\
Gastric carcinoma & $0 / 10$ \\
\hline
\end{tabular}

TSPY = testis-specific protein $\quad$ Y-encoded; $\quad H C C=$ hepatocellular carcinoma; $\mathrm{NSCLC}=$ non-small-cell lung carcinoma

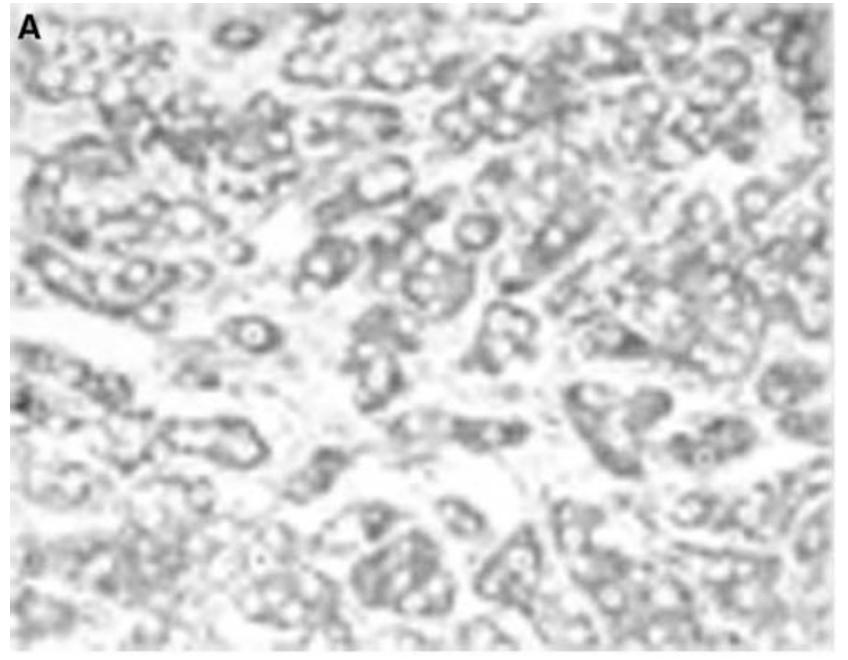

B

igure 2 In situ hybridisation of TSPY mRNA. In situ hybridizstion was performed on human HCC tissues with an antisense or sense oligonucleotide probe against TSPY mRNA. (A) HCC tissue with antisense probe. (B) HCC tissue with sense probe as a control.

encoded protein was also detected by Western blot in COS7 cells transiently transfected with pcDNA-TSPY-FLAG plasmid using anti-FLAG Ab, the molecular weight is approximately $48 \mathrm{kDa}$.

\section{Survey of anti-TSPY seroreactivity in HCC patients}

To get an impression of the frequency of anti-TSPY antibodies, the sera of 106 HCC patients and 46 healthy controls were tested for $\mathrm{Ab}$ reactivity against recombinant TSPY by Western blot (Figure 4). 

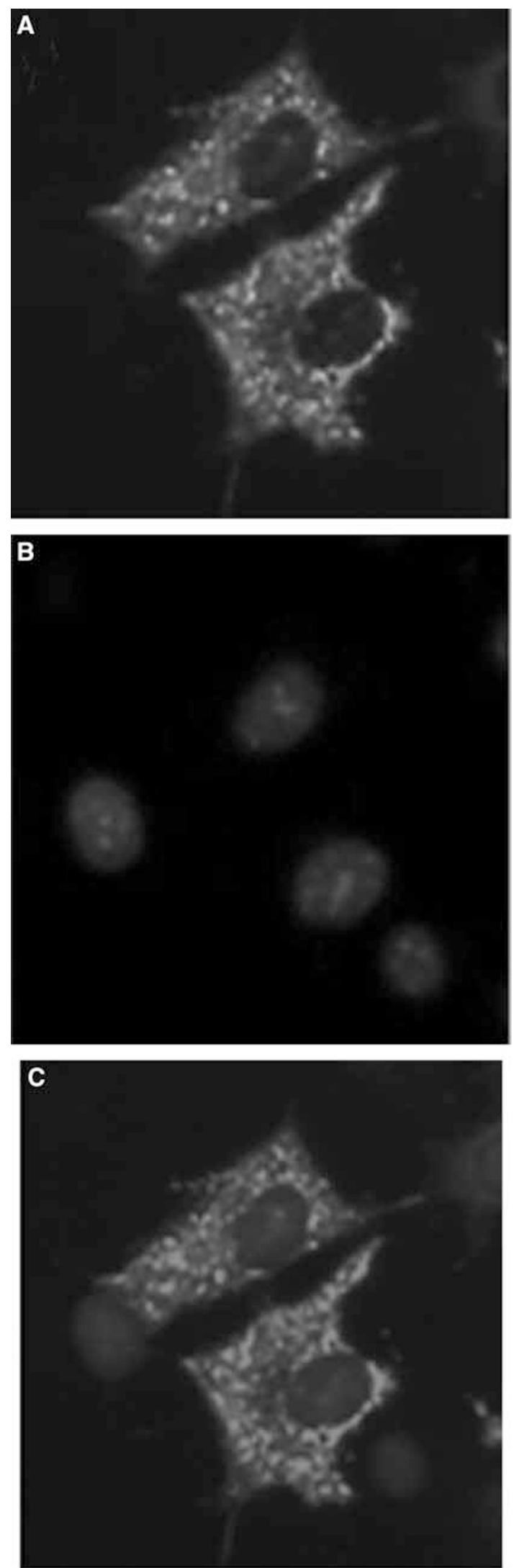

Figure 3 Subcellular localisation of TSPY protein. COS7 cells were transfected with pcDNA-TSPY-FLAG for $24 \mathrm{~h}$, the expressed protein was then detected. (A) TSPY protein was mostly distributed in the cytoplasm as detected by immunofluorescence. (B) Nuclei stained with Hoechst33342. (C) Merged images of $(\mathbf{A})$ and $(\mathbf{B})$.

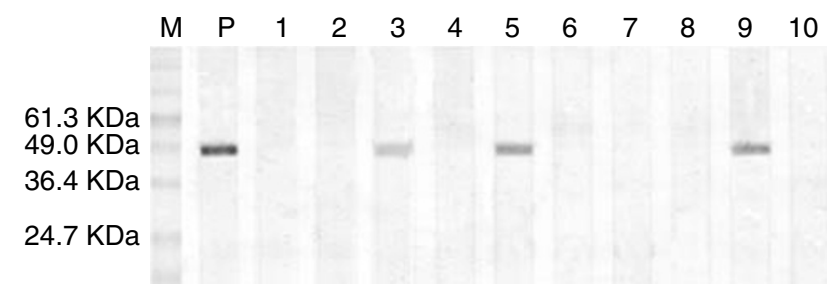

Figure 4 Serological reactivity of the recombinant TSPY protein in HCC patients. The antibody in serum samples was assessed by Western blot assay. M: protein marker; P: positive control; lanes I and 2: negative controls with normal sera; lanes 3, 5, and 9: positive reaction with sera from $\mathrm{HCC}$ patients; lanes 4, 6-8, and I0: negative reaction with sera from HCC patients.

Seven HCC patients had serum Ab responses specific to recombinant TSPY protein (6.6\%), whereas all the healthy controls were negative.

\section{DISCUSSION}

A prerequisite for a broad application of antigen-based vaccine for immunotherapy is the identification of a wide spectrum of immunogenic tumour antigens expressed predominately in human cancers (Kalos, 2003; Scanlan et al, 2004). Cancer/testis antigens are attractive targets in immunotherapy for their limited expression in normal tissue of testis, an immunological privileged site unable to provoke immune responses. To date, $44 \mathrm{CT}$ gene families have been identified; however, the protein products of only three gene families have been found to induce coordinated humoral and cellular responses, including NY-ESO-1, MAGE-A, and SSX antigens (Scanlan et al, 2004). Some preliminary results have been reported for immunotherapy with MAGE-derived peptides (Marchand et al, 1995; Toungouz et al, 2001) and NY-ESO-1 peptide or protein (Jager et al, 2000; Chen et al, 2004; Davis et al, 2004). In this study, we have demonstrated that TSPY is a novel CT antigen.

Our examination of TSPY mRNA expression pattern has confirmed previous reports (Zhang et al, 1992; Schnieders et al, 1996) that human TSPY was not expressed in normal tissues except for testis. Importantly, we found the TSPY transcript was selectively expressed in different histological human tumours and tumour cell lines with the dominant expression in HCC. Since TSPY mRNA was reported to be sequence diversity, direct sequencing of cDNAs prepared from HCC and testicular tissues has been performed. Testis-specific protein Y-encoded transcript from HCC was found to be identical to that from testis, and both belong to TSPY major type encoding a protein of 308 amino acids as identified by Schnieders et al (1996). The expression profile of TSPY in normal tissues, tumour samples and tumour cell lines has categorised this gene in the group of CT antigens. Testis-specific protein Y-encoded differs from the known CT antigens by its chromosomal localisation. Most of the hitherto known CT antigens have been mapped to the $\mathrm{X}$ chromosome with the exception of a few CT antigens that have been mapped to autosome (Scanlan et al, 2002; Lee et al, 2003; Loriot et al, 2003). Testis-specific protein $\mathrm{Y}$-encoded gene was located on human proximal Yp, within the GBY (gonadoblastoma locus on the $\mathrm{Y}$ chromosome) critical region (Lau et al, 2000). Since HCC is three to four times more often in men than women (Kew, 2002; El-Serag, 2004), the relatively high frequency of TSPY in HCC patients might be of significance in aetiology and therapeutics.

The biological function of most CT antigens is unclear except for a few CT antigens, such as SCP-1, which is involved in meiotic chromosome pairing (Tureci et al, 1998); OY-TES-1, involved in the packaging of acrosin in the sperm head (Baba et al, 1994); 
CT15/fertilin $\beta$, involved in egg/sperm membrane interactions (Vidaeus et al, 1997; Primakoff and Myles, 2000); SSX, reported to have a transcription-repressor function (Brett et al, 1997). Testisspecific protein $\mathrm{Y}$-encoded is evolutionarily conserved on the mammalian Y chromosome, its homologous gene families have been found in great apes (Kim and Takenaka, 1996), cattle (Vogel et al, 1997), monkey (Kim et al, 1997), and other mammal (Lau, 1999). These suggest that TSPY might be an important gene acting in male germ cell generation. Testis-specific protein Y-encoded has been indeed reported to function in early spermatogenesis, immediately prior to the spermatogonia to spermatocyte transition (Schnieders et al, 1996). Detailed database and sequence analysis suggest that TSPY belongs to a superprotein family, which includes the proto-oncogene $S E T$ and the nucleosome-assembly factor $N A P-1$, both interact specifically with mitotic cyclin B and are suggested to play a role in DNA replication (Schnieders et al, 1996). SET has been identified as a potent inhibitor of protein phosphatase $2 \mathrm{~A}$, a major mammalian protein serine threonine phosphatase that regulates diverse cellular processes ( $\mathrm{Li}$ et al, 1996). Recently, $S E T$ was found to be an inhibitor of tumour suppressor gene NM-23H1 (Fan et al, 2003), and involved in Galpha(12)-mediated signalling pathways (Kumar et al, 2004). In addition, NAP-1 is needed in a transcriptional activation in cooperation with p300 (Asahara et al, 2002). Advances in the characterisation of SET/NAP functions may provide some important clues to the biological role of the TSPY gene not only in spermatogenesis but also in hepatocarcinogenesis.

\section{REFERENCES}

Asahara H, Tartare-Deckert S, Nakagawa T, Ikehara T, Hirose F, Hunter T, Ito T, Montminy M (2002) Dual roles of p300 in chromatin assembly and transcriptional activation in cooperation with nucleosome assembly protein 1 in vitro. Mol Cell Biol 22: 2974-2983

Baba T, Niida Y, Michikawa Y, Kashiwabara S, Kodaira K, Takenaka M, Kohno N, Gerton GL, Arai Y (1994) An acrosomal protein, sp32, in mammalian sperm is a binding protein specific for two proacrosins and an acrosin intermediate. J Biol Chem 269: 10133 - 10140

Brett D, Whitehouse S, Antonson P, Shipley J, Cooper C, Goodwin G (1997) The SYT protein involved in the $\mathrm{t}(\mathrm{X} ; 18)$ synovial sarcoma translocation is a transcriptional activator localised in nuclear bodies. Hum Mol Genet 6: $1559-1564$

Butterfield LH (2004) Immunotherapeutic strategies for hepatocellular carcinoma. Gastroenterology 127: S232-S241

Butterfield LH, Ribas A (2002) Immunotherapy of hepatocellular carcinoma. Expert Opin Biol Ther 2: 123-133

Chen Q, Jackson H, Parente P, Luke T, Rizkalla M, Tai TY, Zhu HC, Mifsud NA, Dimopoulos N, Masterman KA, Hopkins W, Goldie H, Maraskovsky E, Green S, Miloradovic L, McCluskey J, Old LJ, Davis ID, Cebon J, Chen $\mathrm{W}$ (2004) Immunodominant CD4+ responses identified in a patient vaccinated with full-length NY-ESO-1 formulated with ISCOMATRIX adjuvant. Proc Natl Acad Sci USA 101: 9363-9368

Davis ID, Chen W, Jackson H, Parente P, Shackleton M, Hopkins W, Chen Q, Dimopoulos N, Luke T, Murphy R, Scott AM, Maraskovsky E, McArthur G, MacGregor D, Sturrock S, Tai TY, Green S, Cuthbertson A, Maher D, Miloradovic L, Mitchell SV, Ritter G, Jungbluth AA, Chen YT, Gnjatic S, Hoffman EW, Old LJ, Cebon JS (2004) Recombinant NY-ESO-1 protein with ISCOMATRIX adjuvant induces broad integrated antibody and CD4(+) and CD8(+) T cell responses in humans. Proc Natl Acad Sci USA 101: $10697-10702$

El-Serag HB (2004) Hepatocellular carcinoma: recent trends in the United States. Gastroenterology 127: S27-S34

Fan Z, Beresford PJ, Oh DY, Zhang D, Lieberman J (2003) Tumor suppressor NM23-H1 is a granzyme A-activated DNase during CTLmediated apoptosis, and the nucleosome assembly protein SET is its inhibitor. Cell 112: 659-672

Iizuka N, Oka M, Yamada-Okabe H, Mori N, Tamesa T, Okada T, Takemoto N, Tangoku A, Hamada K, Nakayama H, Miyamoto T, Uchimura S, Hamamoto Y (2002) Comparison of gene expression profiles between hepatitis $B$ virus- and hepatitis $C$ virus-infected hepatocellular carcinoma
In this study, the expression of TSPY mRNA in HCC was relevant to tumour differentiation status. Testis-specific protein Y-encoded was expressed at high proportion $(50 \%)$ in WD HCC and relatively small proportion (16\%) in PD HCC. It is well known that the HCC often shows dedifferentiation from WD HCC to PD HCC during multistep progression (Mise et al, 1998; Sakamoto et al, 1991). The different expression frequencies of TSPY transcript in WD and PD, together with the structure relationship of TSPY to SET and NAP, suggests that TSPY possibly involve in hepatocarcinogenesis and reversely involve in progression of HCC.

A serological survey has shown that seven of 106 HCC patients exhibited spontaneous humoral immune response to TSPY. Although the frequency of $\mathrm{Ab}$ response in HCC patients is low as most of the other CT antigens, the TSPY in vivo is immunogenic. Further investigation on the TSPY-mediated T-cell immune response is in process. The restricted expression in tumours and testis and its immunogenicity imply that TSPY is a potential vaccine candidate for immunotherapy in HCC.

\section{ACKNOWLEDGEMENTS}

This work was supported by grants from Ludwig Institute for Cancer Research (KSP 003), China National 863 Program (2003AA215110), and Beijing Municipal Government Foundation for National Sciences (7001002). by oligonucleotide microarray data on the basis of a supervised learning method. Cancer Res 62: 3939-3944

Iwashita Y, Tahara K, Goto S, Sasaki A, Kai S, Seike M, Chen CL, Kawano K, Kitano S (2003) A phase I study of autologous dendritic cell-based immunotherapy for patients with unresectable primary liver cancer. Cancer Immunol Immunother 52: 155-161

Jager E, Gnjatic S, Nagata Y, Stockert E, Jager D, Karbach J, Neumann A, Rieckenberg J, Chen YT, Ritter G, Hoffman E, Arand M, Old LJ, Knuth A (2000) Induction of primary NY-ESO-1 immunity: CD8+ T lymphocyte and antibody responses in peptide-vaccinated patients with NY-ESO-1+ cancers. Proc Natl Acad Sci USA 97: 12198 - 12203

Kalos M (2003) Tumor antigen-specific T cells and cancer immunotherapy: current issues and future prospects. Vaccine 21: 781-786

Kew MC (2002) Epidemiology of hepatocellular carcinoma. Toxicology 181 - 182: $35-38$

Kim HS, Kageyama T, Nakamura S, Takenaka O (1997) Nucleotide sequence of cDNA and the gene expression of testis-specific protein $\mathrm{Y}$ in the Japanese monkey. Zool Sci 14: 609-614

Kim HS, Takenaka O (1996) A comparison of TSPY genes from Ychromosomal DNA of the great apes and humans: sequence, evolution, and phylogeny. Am J Phys Anthropol 100: 301-309

Kuang M, Peng BG, Lu MD, Liang LJ, Huang JF, He Q, Hua YP, Totsuka S, Liu SQ, Leong KW, Ohno T (2004) Phase II randomized trial of autologous formalin-fixed tumor vaccine for postsurgical recurrence of hepatocellular carcinoma. Clin Cancer Res 10: $1574-1579$

Kumar RN, Radhakrishnan R, Ha JH, Dhanasekaran N (2004) Proteome analysis of NIH3T3 cells transformed by activated Galpha12: regulation of leukemia-associated protein SET. J Proteome Res 3: 1177-1183

Lau Y, Chou P, Iezzoni J, Alonzo J, Komuves L (2000) Expression of a candidate gene for the gonadoblastoma locus in gonadoblastoma and testicular seminoma. Cytogenet Cell Genet 91: 160-164

Lau YF (1999) Gonadoblastoma, testicular and prostate cancers, and the TSPY gene. Am J Hum Genet 64: 921 - 927

Lee SY, Obata Y, Yoshida M, Stockert E, Williamson B, Jungbluth AA, Chen YT, Old LJ, Scanlan MJ (2003) Immunomic analysis of human sarcoma. Proc Natl Acad Sci USA 100: 2651-2656

Li M, Makkinje A, Damuni Z (1996) The myeloid leukemia-associated protein SET is a potent inhibitor of protein phosphatase 2A.J Biol Chem 271: $11059-11062$ 
Llovet JM, Burroughs A, Bruix J (2003) Hepatocellular carcinoma. Lancet 362: $1907-1917$

Loriot A, Boon T, De Smet C (2003) Five new human cancer-germline genes identified among 12 genes expressed in spermatogonia. Int J Cancer 105: $371-376$

Marchand M, Weynants P, Rankin E, Arienti F, Belli F, Parmiani G, Cascinelli N, Bourlond A, Vanwijck R, Humblet Y, Canon JL, Laurent C, Naeyaert JM, Plagne R, Deraemaeker R, Knuth A, Jager E, Brasseur F, Herman J, Coulle PG, Boon T (1995) Tumor regression responses in melanoma patients treated with a peptide encoded by gene MAGE-3. Int J Cancer 63: $883-885$

Mise K, Tashiro S, Yogita S, Wada D, Harada M, Fukuda Y, Miyake H, Isikawa M, Izumi K, Sano N (1998) Assessment of the biological malignancy of hepatocellular carcinoma: relationship to clinicopathological factors and prognosis. Clin Cancer Res 4: 1475-1482

Okabe H, Satoh S, Kato T, Kitahara O, Yanagawa R, Yamaoka Y, Tsunoda T, Furukawa Y, Nakamura Y (2001) Genome-wide analysis of gene expression in human hepatocellular carcinomas using cDNA microarray: identification of genes involved in viral carcinogenesis and tumor progression. Cancer Res 61: 2129-2137

Primakoff P, Myles DG (2000) The ADAM gene family: surface proteins with adhesion and protease activity. Trends Genet 16: 83-87

Sakamoto M, Hirohashi S, Shimosato Y (1991) Early stages of multistep hepatocarcinogenesis: adenomatous hyperplasia and early hepatocellular carcinoma. Hum Pathol 22: $172-178$

Scanlan MJ, Gure AO, Jungbluth AA, Old LJ, Chen YT (2002) Cancer/testis antigens: an expanding family of targets for cancer immunotherapy. Immunol Rev 188: $22-32$

Scanlan MJ, Simpson AJ, Old LJ (2004) The cancer/testis genes: review, standardization, and commentary. Cancer Immun 4:
Schnieders F, Dork T, Arnemann J, Vogel T, Werner M, Schmidtke J (1996) Testis-specific protein, Y-encoded (TSPY) expression in testicular tissues. Hum Mol Genet 5: 1801-1807

Shi YY, Wang HC, Yin YH, Sun WS, Li Y, Zhang CQ, Wang Y, Wang S, Chen WF (2005) Identification and analysis of tumour-associated antigens in hepatocellular carcinoma. $\mathrm{Br} \mathrm{J}$ Cancer 92: $929-934$

Smith MW, Yue ZN, Geiss GK, Sadovnikova NY, Carter VS, Boix L, Lazaro CA, Rosenberg GB, Bumgarner RE, Fausto N, Bruix J, Katze MG (2003) Identification of novel tumor markers in hepatitis $\mathrm{C}$ virus-associated hepatocellular carcinoma. Cancer Res 63: 859-864

Toungouz M, Libin M, Bulte F, Faid L, Lehmann F, Duriau D, Laporte M, Gangji D, Bruyns C, Lambermont M, Goldman M, Velu T (2001) Transient expansion of peptide-specific lymphocytes producing IFN-gamma after vaccination with dendritic cells pulsed with MAGE peptides in patients with mage-A1/A3-positive tumors. J Leukocyte Biol 69: $937-943$

Tureci O, Sahin U, Zwick C, Koslowski M, Seitz G, Pfreundschuh M (1998) Identification of a meiosis-specific protein as a member of the class of cancer/testis antigens. Proc Natl Acad Sci USA 95: 5211-5216

Vidaeus CM, von Kapp-Herr C, Golden WL, Eddy RL, Shows TB, Herr IC (1997) Human fertilin beta: identification, characterization, and chromosomal mapping of an ADAM gene family member. Mol Reprod Dev 46: $363-369$

Vogel T, Dechend F, Manz E, Jung C, Jakubiczka S, Fehr S, Schmidtke J, Schnieders F (1997) Organization and expression of bovine TSPY. Mamm Genome 8: $491-496$

Zhang JS, Yang-Feng TL, Muller U, Mohandas TK, de Jong PJ, Lau YF (1992) Molecular isolation and characterization of an expressed gene from the human Y chromosome. Hum Mol Genet 1: 717-726 